\title{
A novel 3-D jerk chaotic system with three quadratic nonlinearities and its adaptive control
}

\author{
SUNDARAPANDIAN VAIDYANATHAN
}

\begin{abstract}
This paper announces an eight-term novel 3-D jerk chaotic system with three quadratic nonlinearities. The phase portraits of the novel jerk chaotic system are displayed and the qualitative properties of the jerk system are described. The novel jerk chaotic system has two equilibrium points, which are saddle-foci and unstable. The Lyapunov exponents of the novel jerk chaotic system are obtained as $L_{1}=0.20572, L_{2}=0$ and $L_{3}=-1.20824$. Since the sum of the Lyapunov exponents of the jerk chaotic system is negative, we conclude that the chaotic system is dissipative. The Kaplan-Yorke dimension of the novel jerk chaotic system is derived as $D_{K Y}=2.17026$. Next, an adaptive controller is designed via backstepping control method to globally stabilize the novel jerk chaotic system with unknown parameters. Moreover, an adaptive controller is also designed via backstepping control method to achieve global chaos synchronization of the identical jerk chaotic systems with unknown parameters. The backstepping control method is a recursive procedure that links the choice of a Lyapunov function with the design of a controller and guarantees global asymptotic stability of strict feedback systems. MATLAB simulations have been depicted to illustrate the phase portraits of the novel jerk chaotic system and also the adaptive backstepping control results.
\end{abstract}

Key words: chaos, chaotic system, dissipative chaotic system, adaptive control, backstepping control, synchronization.

\section{Introduction}

Chaos theory describes the qualitative study of unstable aperiodic behavior in deterministic nonlinear dynamical systems. A dynamical system is called chaotic if it satisfies the three properties: boundedness, infinite recurrence and sensitive dependence on initial conditions [1].

A significant development in chaos theory occurred when Lorenz discovered a 3-D chaotic system of a weather model [2]. Subsequently, Rössler discovered a 3-D chaotic system in 1976 [3], which is algebraically simpler than the Lorenz system. Indeed, Lorenz's system is a seven-term chaotic system with two quadratic nonlinearities, while Rössler's system is a seven-term chaotic system with just one quadratic nonlinearity.

The Author is with Research and Development Centre, Vel Tech University, Avadi, Chennai-600062, Tamilnadu, India. E-mail: sundarvtu@gmail.com

Received 8.10.2015. 
Some well-known paradigms of 3-D chaotic systems are Arneodo system [4], Sprott systems [5], Chen system [6], Hénon-Heiles system [7], Lü-Chen system [8], Liu system [9], Cai system [10], T-system [11], etc. Many new chaotic systems have been also discovered like Li system [12], Sundarapandian systems [13, 14], Vaidyanathan systems $[15,16,17,18,19,20,21,22$, 23, 24, 25, 26, 27, 28, 29, 30], Pehlivan system [31], Tacha system [32], Jafari system [33], Sampath system [34], Pham systems [35, 36, 37, 38], etc.

Chaos theory has applications in several fields of science and engineering such as oscillators [39, 40, 41, 42, 43, 44, 45, 46], dynamos [47, 48, 49, 50], Tokamak systems $[51,52]$, chemical reactions $[53,54,55,56,57,58,59,60,61,62]$, neural networks $[63,64,65,66,67,68]$, neurology [69, 70, 71, 72, 73, 74], biology [75, 76, 77, 78, $79,80,81,82,83]$, electrical circuits [84, 85, 86], cryptosystems [87, 88], memristors [89, 90, 91], random bit generator [92], etc.

In this paper, we announce an eight-term novel 3-D jerk chaotic system with three quadratic nonlinearities. The phase portraits of the novel jerk chaotic system are displayed and the mathematical properties are discussed. The novel jerk chaotic system has two equilibrium points, which are saddle-foci and unstable.

The Lyapunov exponents of the novel jerk chaotic system are obtained as $L_{1}=$ $0.20572, L_{2}=0$ and $L_{3}=-1.20824$. Since the sum of the Lyapunov exponents of the jerk chaotic system is negative, we conclude that the chaotic system is dissipative. The Kaplan-Yorke dimension of the novel jerk chaotic system is derived as $D_{K Y}=2.17026$.

Next, using backstepping control method, we derive an adaptive control law that stabilizes the novel conservative chaotic system, when the system parameters are unknown. Using backstepping control method, we also derive an adaptive control law that achieves global chaos synchronization of the identical novel conservative systems with unknown parameters. The backstepping control method is a recursive procedure that links the choice of a Lyapunov function with the design of a controller and guarantees global asymptotic stability of strict feedback systems.

Synchronization of chaotic systems is a phenomenon that may occur when a chaotic oscillator drives another chaotic oscillator. Because of the butterfly effect which causes the exponential divergence of the trajectories of two identical chaotic systems started with nearly the same initial conditions, synchronizing two chaotic systems is seemingly a very challenging problem.

In most of the synchronization approaches, the master-slave or drive-response formalism is used. If a particular chaotic system is called the master or drive system and another chaotic system is called the slave or response system, then the idea of synchronization is to use the output of the master system to control the response of the slave system so that the slave system tracks the output of the master system asymptotically.

In the chaos literature, an impressive variety of techniques have been proposed for chaos synchronization such as active control method [93, 94, 95, 96, 97], adaptive control method [98, 99, 100, 101, 102, 103, 104, 105, 106, 107], backstepping control method $[108,109,110,111,112,113]$, sliding mode control method $[114,115,116,117,118,119]$, etc. 
All the main adaptive backstepping control results in this paper are proved using Lyapunov stability theory [120]. MATLAB simulations are depicted to illustrate the phase portraits of the novel jerk chaotic system, adaptive stabilization and synchronization results for the novel 3-D jerk chaotic system.

\section{A 3-D novel jerk chaotic system}

In this section, we describe an eight-term novel 3-D jerk chaotic system with three quadratic nonlinearities, which is described by the dynamics

$$
\begin{aligned}
& \dot{x}_{1}=x_{2} \\
& \dot{x}_{2}=x_{3} \\
& \dot{x}_{3}=a x_{1}-b x_{2}-x_{3}+c x_{1} x_{2}-p\left(x_{1}^{2}+x_{2}^{2}\right)
\end{aligned}
$$

where $x_{1}, x_{2}, x_{3}$ are the states and $a, b, c, p$ are constant, positive, parameters of the system.

The system (1) exhibits a strange chaotic attractor for the values

$$
a=7.5, b=4, c=0.03, p=0.9
$$

For numerical simulations, we take the initial conditions of the state $x(t)$ as

$$
x_{1}(0)=1.8, x_{2}(0)=1.3, x_{3}=1.6
$$

Figure 1 shows the 3-D phase portrait of the strange chaotic attractor of the system (1). Figures 2-4 show the 2-D projection of the strange chaotic attractor of the system (1) on $\left(x_{1}, x_{2}\right),\left(x_{2}, x_{3}\right)$ and $\left(x_{1}, x_{3}\right)$ planes, respectively.

\section{Analysis of the 3-D novel jerk chaotic system}

\subsection{Dissipativity}

In vector notation, the new jerk system (1) can be expressed as

$$
\dot{\boldsymbol{x}}=f(\boldsymbol{x})=\left[\begin{array}{l}
f_{1}\left(x_{1}, x_{2}, x_{3}\right) \\
f_{2}\left(x_{1}, x_{2}, x_{3}\right) \\
f_{3}\left(x_{1}, x_{2}, x_{3}\right)
\end{array}\right]
$$

where

$$
\left\{\begin{array}{l}
f_{1}\left(x_{1}, x_{2}, x_{3}\right)=x_{2} \\
f_{2}\left(x_{1}, x_{2}, x_{3}\right)=x_{3} \\
f_{3}\left(x_{1}, x_{2}, x_{3}\right)=a x_{1}-b x_{2}-x_{3}+c x_{1} x_{2}-p\left(x_{1}^{2}+x_{2}^{2}\right)
\end{array}\right.
$$




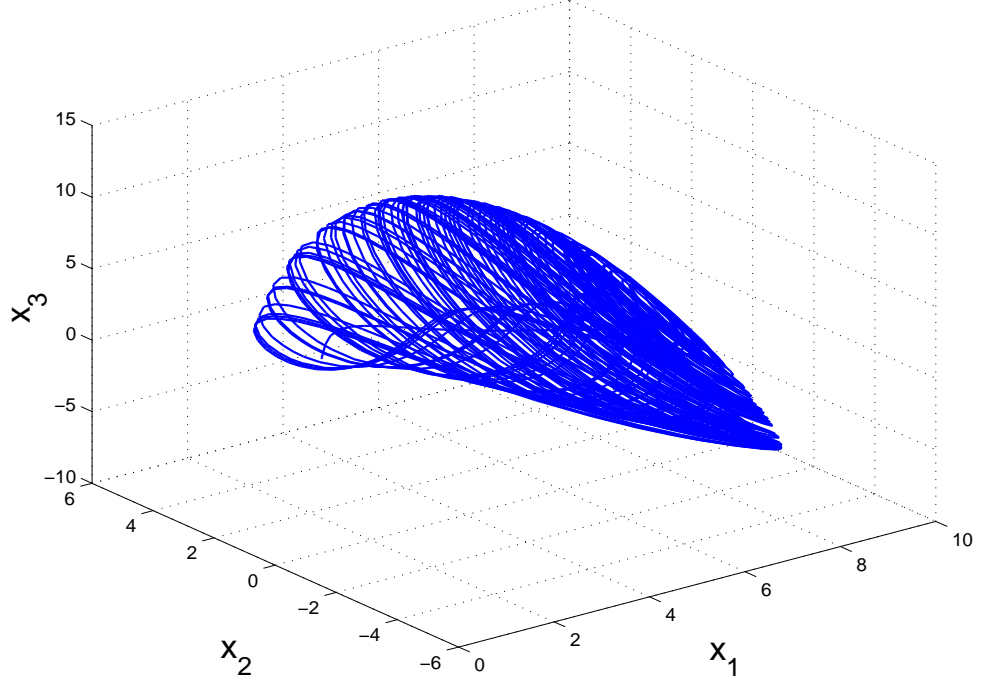

Figure 1. Strange attractor of the 3-D novel jerk chaotic System

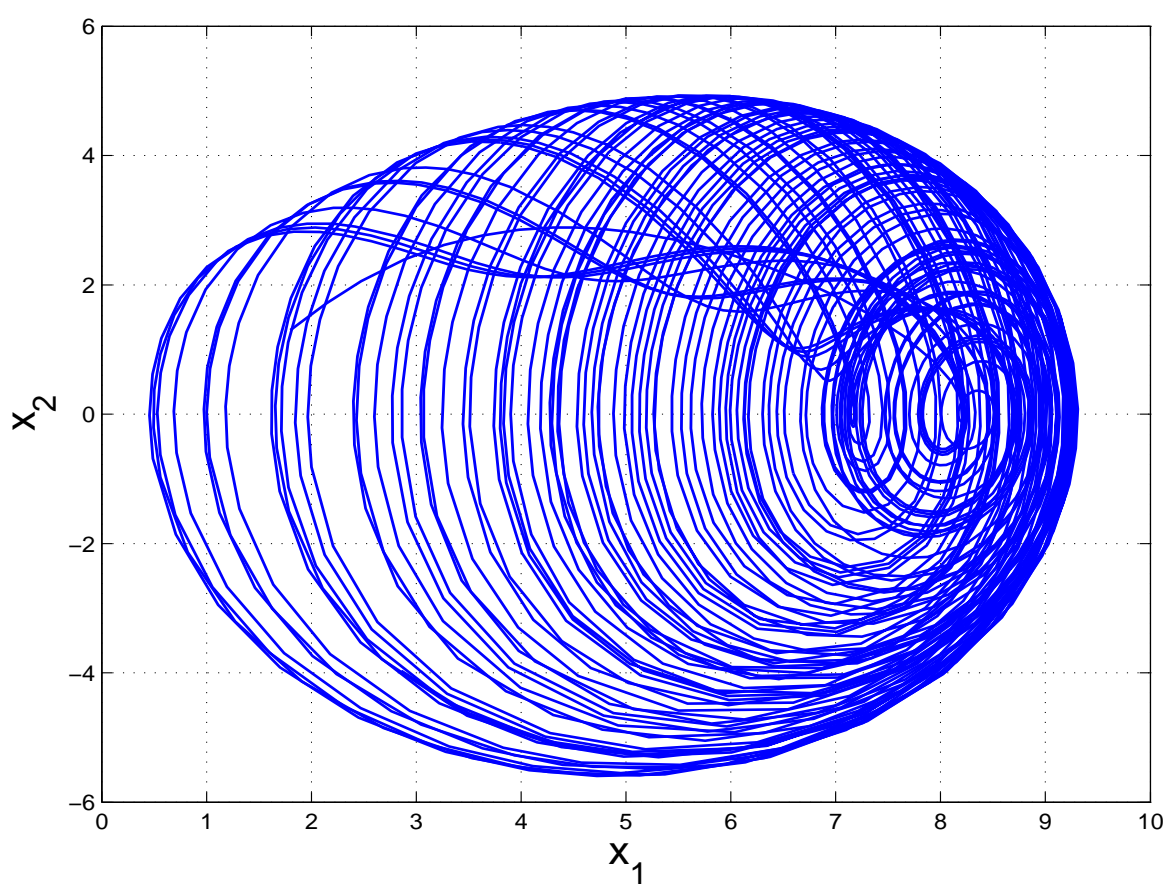

Figure 2. 2-D projection of the novel jerk chaotic system on the $\left(x_{1}, x_{2}\right)$ plane 


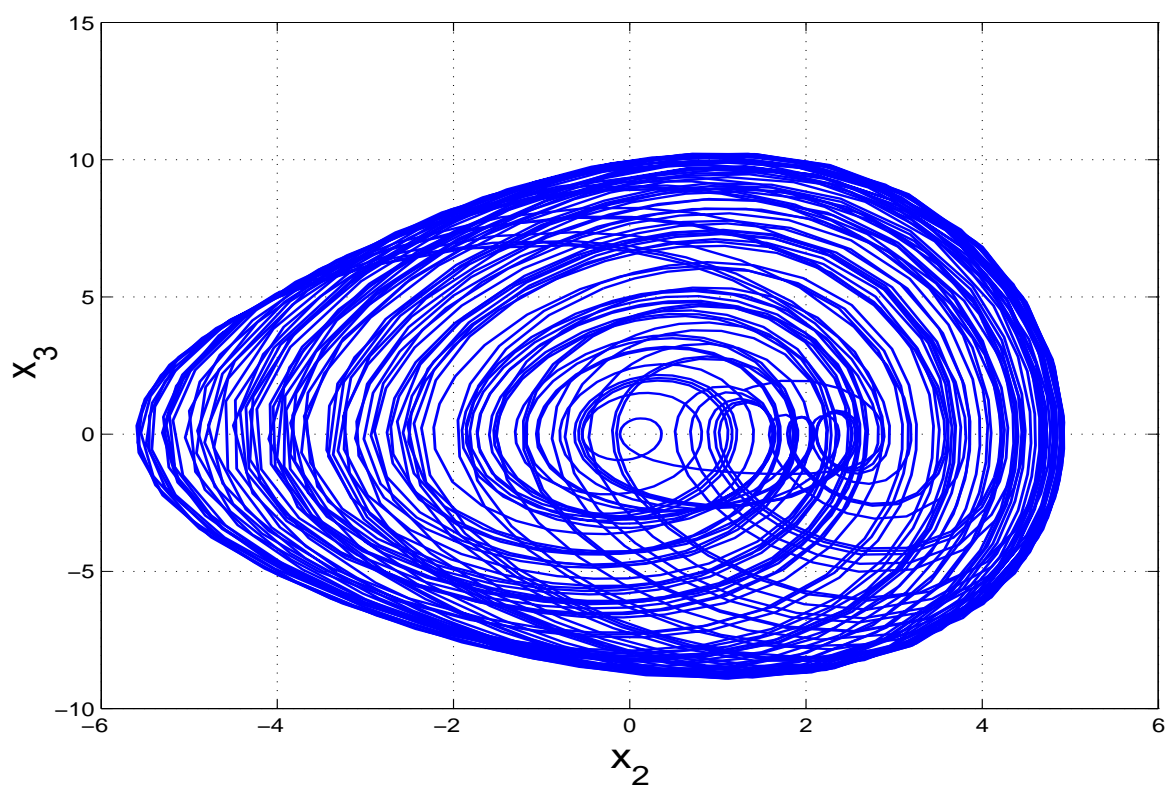

Figure 3. 2-D projection of the novel jerk chaotic system on the $\left(x_{2}, x_{3}\right)$ plane

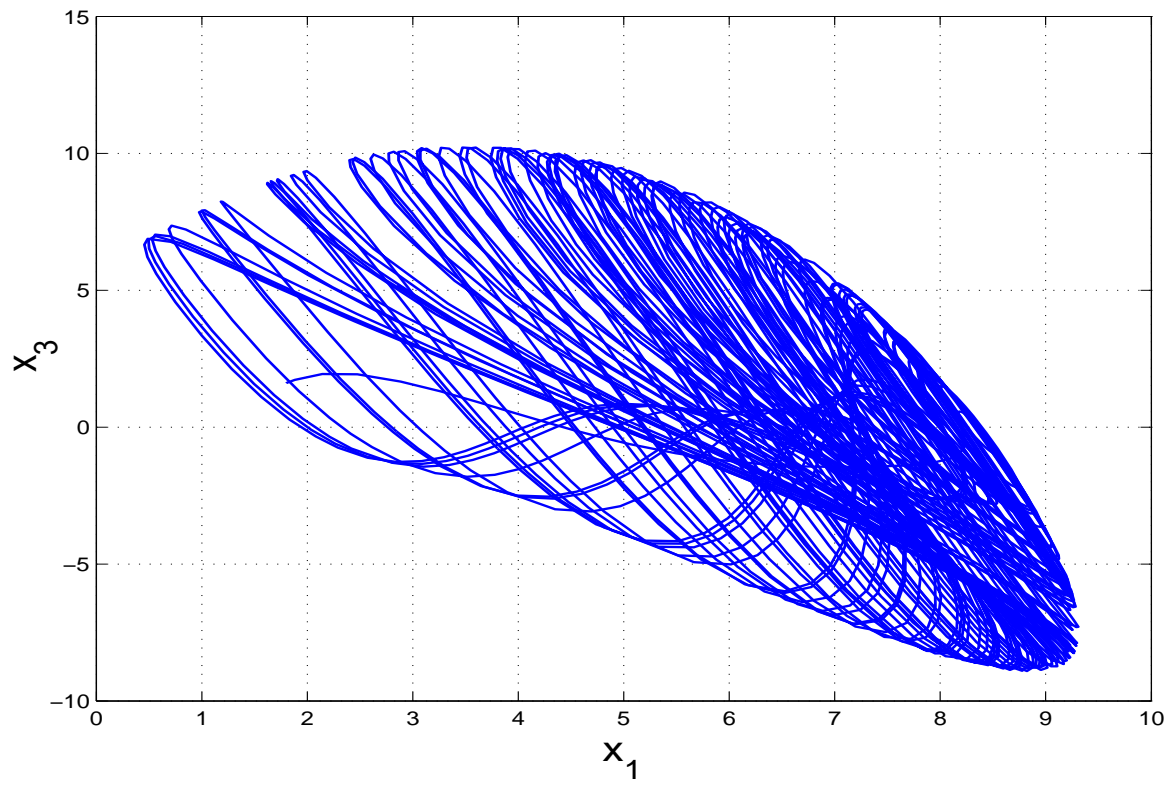

Figure 4. 2-D projection of the novel jerk chaotic system on the $\left(x_{1}, x_{3}\right)$ plane 
Let $\Omega$ be any region in $\Re^{3}$ with a smooth boundary and also, $\Omega(t)=\Phi_{t}(\Omega)$, where $\Phi_{t}$ is the flow of $f$. Furthermore, let $V(t)$ denote the volume of $\Omega(t)$.

By Liouville's theorem, we know that

$$
\dot{V}(t)=\int_{\Omega(t)}(\nabla \cdot f) d x_{1} d x_{2} d x_{3}
$$

The divergence of the novel jerk system (4) is found as:

$$
\nabla \cdot f=\frac{\partial f_{1}}{\partial x_{1}}+\frac{\partial f_{2}}{\partial x_{2}}+\frac{\partial f_{3}}{\partial x_{3}}=-1<0
$$

Inserting the value of $\nabla \cdot f$ from (7) into (6), we get

$$
\dot{V}(t)=\int_{\Omega(t)}(-1) d x_{1} d x_{2} d x_{3}=-V(t)
$$

Integrating the first order linear differential equation (8), we get

$$
V(t)=\exp (-t) V(0)
$$

From Eq. (9), it is clear that $V(t) \rightarrow 0$ exponentially as $t \rightarrow \infty$. This shows that the novel 3-D jerk chaotic system (1) is dissipative. Hence, the system limit sets are ultimately confined into a specific limit set of zero volume, and the asymptotic motion of the novel jerk chaotic system (1) settles onto a strange attractor of the system.

\subsection{Equilibrium Points}

The equilibrium points of the 3-D novel jerk chaotic system (1) are obtained by solving the equations

$$
\left.\begin{array}{llcl}
f_{1}\left(x_{1}, x_{2}, x_{3}\right) & = & x_{2} & = \\
f_{2}\left(x_{1}, x_{2}, x_{3}\right) & = & x_{3} & = \\
f_{3}\left(x_{1}, x_{2}, x_{3}\right) & =a x_{1}-b x_{2}-x_{3}+c x_{1} x_{2}-p\left(x_{1}^{2}+x_{2}^{2}\right) & = & 0
\end{array}\right\}
$$

We take the parameter values as in the chaotic case (2), i.e.

$$
a=7.5, b=4, c=0.03, p=0.9
$$

Thus, the equilibrium points of the system (1) are characterized by the equations

$$
x_{1}\left(a-p x_{1}\right)=0, x_{2}=0, x_{3}=0
$$

Solving the system (12), we get the equilibrium points of the system (1) as

$$
E_{0}=\left[\begin{array}{l}
0 \\
0 \\
0
\end{array}\right] \text { and } E_{1}=\left[\begin{array}{c}
8.3333 \\
0 \\
0
\end{array}\right]
$$


To test the stability type of the equilibrium points $E_{0}$ and $E_{1}$, we calculate the Jacobian matrix of the novel jerk chaotic system (1) at any point $x$ :

$$
J(\boldsymbol{x})=\left[\begin{array}{ccc}
0 & 1 & 0 \\
0 & 0 & 1 \\
7.5+0.03 x_{2}-1.8 x_{1} & -4+0.03 x_{1}-1.8 x_{2} & -1
\end{array}\right]
$$

We note that

$$
J_{0} \triangleq J\left(E_{0}\right)=\left[\begin{array}{ccc}
0 & 1 & 0 \\
0 & 0 & 1 \\
7.5 & -4 & -1
\end{array}\right]
$$

which has the eigenvalues

$$
\lambda_{1}=1.1555, \lambda_{2,3}=-1.0778 \pm 2.3085 i
$$

This shows that the equilibrium point $E_{0}$ is a saddle-focus point.

Next, we note that

$$
\left.J_{1} \triangleq J_{1}\right)=\left[\begin{array}{ccc}
0 & 1 & 0 \\
0 & 0 & 1 \\
-7.4999 & -3.7500 & -1
\end{array}\right]
$$

which has the eigenvalues

$$
\lambda_{1}=-1.5956, \lambda_{2,3}=0.2978 \pm 2.1475 i
$$

This shows that the equilibrium point $E_{1}$ is also a saddle-focus point.

Hence, the novel jerk chaotic system (1) has two equilibrium points $E_{0}, E_{1}$ defined by (13), which are saddle-foci and unstable.

\subsection{Lyapunov exponents and Kaplan-Yorke dimension}

We take the parameter values of the novel jerk system (1) as

$$
a=7.5, b=4, c=0.03, p=0.9
$$

Then the Lyapunov exponents are numerically obtained using MATLAB as

$$
L_{1}=0.20572, L_{2}=0, L_{3}=-1.20824
$$

Thus, the maximal Lyapunov exponent (MLE) of the novel jerk system (1) is positive, which means that the system has a chaotic behavior.

Since $L_{1}+L_{2}+L_{3}=-1.00252<0$, it follows that the novel jerk chaotic system (1) is dissipative.

Also, the Kaplan-Yorke dimension of the novel jerk chaotic system (1) is obtained as

$$
D_{K Y}=2+\frac{L_{1}+L_{2}}{\left|L_{3}\right|}=2.17026,
$$

which is fractional. 


\section{Adaptive control of the 3-D novel jerk chaotic system}

In this section, we use backstepping control method to derive an adaptive feedback control law for globally stabilizing the 3-D novel jerk chaotic system with unknown parameters.

Thus, we consider the 3-D novel jerk chaotic system given by

$$
\left\{\begin{array}{l}
\dot{x}_{1}=x_{2} \\
\dot{x}_{2}=x_{3} \\
\dot{x}_{3}=a x_{1}-b x_{2}-x_{3}+c x_{1} x_{2}-p\left(x_{1}^{2}+x_{2}^{2}\right)+u
\end{array}\right.
$$

where $a, b, c, p$ are unknown constant parameters, and $u$ is a backstepping control law to be determined using estimates of the unknown system parameters.

The parameter estimation errors are defined as:

$$
\left\{\begin{array}{l}
e_{a}(t)=a-\hat{a}(t) \\
e_{b}(t)=b-\hat{b}(t) \\
e_{c}(t)=c-\hat{c}(t) \\
e_{p}(t)=p-\hat{p}(t)
\end{array}\right.
$$

Differentiating (23) with respect to $t$, we obtain the following equations:

$$
\left\{\begin{array}{l}
\dot{e}_{a}(t)=-\dot{\hat{a}}(t) \\
\dot{e}_{b}(t)=-\dot{\hat{b}}(t) \\
\dot{e}_{c}(t)=-\dot{\hat{c}}(t) \\
\dot{e}_{p}(t)=-\dot{\hat{p}}(t)
\end{array}\right.
$$

Next, we shall state and prove the main result of this section.

Theorem 1 The 3-D novel jerk chaotic system (22), with unknown parameters $a$ and $b$, is globally and exponentially stabilized by the adaptive feedback control law,

$$
u(t)=-[3+\hat{a}(t)] x_{1}-[5-\hat{b}(t)] x_{2}-2 x_{3}-\hat{c}(t) x_{1} x_{2}+\hat{p}(t)\left(x_{1}^{2}+x_{2}^{2}\right)-k z_{3}
$$

where $k>0$ is a gain constant,

$$
z_{3}=2 x_{1}+2 x_{2}+x_{3}
$$


and the update law for the parameter estimates $\hat{a}(t), \hat{b}(t), \hat{c}(t), \hat{p}(t)$ is given by

$$
\left\{\begin{array}{l}
\dot{\hat{a}}(t)=x_{1} z_{3} \\
\dot{\hat{b}}(t)=-x_{2} z_{3} \\
\dot{\hat{c}}(t)=x_{1} x_{2} z_{3} \\
\dot{\hat{p}}(t)=-\left(x_{1}^{2}+x_{2}^{2}\right) z_{3}
\end{array}\right.
$$

Proof We prove this result via backstepping control method and Lyapunov stability theory.

First, we define a quadratic Lyapunov function

$$
V_{1}\left(z_{1}\right)=\frac{1}{2} z_{1}^{2}
$$

where

$$
z_{1}=x_{1}
$$

Differentiating $V_{1}$ along the dynamics (22), we get

$$
\dot{V}_{1}=z_{1} \dot{z}_{1}=x_{1} x_{2}=-z_{1}^{2}+z_{1}\left(x_{1}+x_{2}\right)
$$

Now, we define

$$
z_{2}=x_{1}+x_{2}
$$

Using (31), we can simplify the equation (30) as

$$
\dot{V}_{1}=-z_{1}^{2}+z_{1} z_{2}
$$

Secondly, we define a quadratic Lyapunov function

$$
V_{2}\left(z_{1}, z_{2}\right)=V_{1}\left(z_{1}\right)+\frac{1}{2} z_{2}^{2}=\frac{1}{2}\left(z_{1}^{2}+z_{2}^{2}\right)
$$

Differentiating $V_{2}$ along the dynamics (22), we get

$$
\dot{V}_{2}=-z_{1}^{2}-z_{2}^{2}+z_{2}\left(2 x_{1}+2 x_{2}+x_{3}\right)
$$

Now, we define

$$
z_{3}=2 x_{1}+2 x_{2}+x_{3}
$$

Using (35), we can simplify the equation (34) as

$$
\dot{V}_{2}=-z_{1}^{2}-z_{2}^{2}+z_{2} z_{3}
$$

Finally, we define a quadratic Lyapunov function

$$
V\left(z_{1}, z_{2}, z_{3}, e_{a}, e_{b}, e_{c}, e_{p}\right)=V_{2}\left(z_{1}, z_{2}\right)+\frac{1}{2} z_{3}^{2}+\frac{1}{2}\left(e_{a}^{2}+e_{b}^{2}+e_{c}^{2}+e_{p}^{2}\right)
$$


which is a positive definite function on $\Re^{7}$.

Differentiating $V$ along the dynamics (22), we get

$$
\dot{V}=-z_{1}^{2}-z_{2}^{2}-z_{3}^{2}+z_{3}\left(z_{3}+z_{2}+\dot{z}_{3}\right)-e_{a} \dot{\hat{a}}-e_{b} \dot{\hat{b}}-e_{c} \dot{\hat{c}}-e_{p} \dot{\hat{p}}
$$

Eq. (38) can be written compactly as

$$
\dot{V}=-z_{1}^{2}-z_{2}^{2}-z_{3}^{2}+z_{3} S-e_{a} \dot{\hat{a}}-e_{b} \dot{\hat{b}}-e_{c} \dot{\hat{c}}-e_{p} \dot{\hat{p}}
$$

where

$$
S=z_{3}+z_{2}+\dot{z}_{3}=z_{3}+z_{2}+2 \dot{x}_{1}+2 \dot{x}_{2}+\dot{x}_{3}
$$

A simple calculation gives

$$
S=(3+a) x_{1}+(5-b) x_{2}+2 x_{3}+c x_{1} x_{2}-p\left(x_{1}^{2}+x_{2}^{2}\right)+u
$$

Substituting the adaptive control law (25) into (41), we obtain

$$
S=[a-\hat{a}(t)] x_{1}-[b-\hat{b}(t)] x_{2}+[c-\hat{c}(t)] x_{1} x_{2}-[p-\hat{p}(t)]\left(x_{1}^{2}+x_{2}^{2}\right)-k z_{3}
$$

Using the definitions (24), we can simplify (42) as

$$
S=e_{a} x_{1}-e_{b} x_{2}+e_{c} x_{1} x_{2}-e_{p}\left(x_{1}^{2}+x_{2}^{2}\right)-k z_{3}
$$

Substituting the value of $S$ from (43) into (39), we obtain

$$
\left\{\begin{aligned}
\dot{V}= & -z_{1}-z_{2}-(1+k) z_{3}^{2}+e_{a}\left[x_{1} z_{3}-\dot{\hat{a}}\right]+e_{b}\left[-x_{2} z_{3}-\dot{\hat{b}}\right] \\
& +e_{c}\left[x_{1} x_{2} z_{3}-\dot{\hat{c}}\right]+e_{p}\left[-\left(x_{1}^{2}+x_{2}^{2}\right) z_{3}-\dot{\hat{p}}\right]
\end{aligned}\right.
$$

Substituting the update law (27) into (44), we get

$$
\dot{V}=-z_{1}^{2}-z_{2}^{2}-(1+k) z_{3}^{2},
$$

which is a negative semi-definite function on $\Re^{7}$.

From (45), it follows that the vector $\boldsymbol{z}(t)=\left(z_{1}(t), z_{2}(t), z_{3}(t)\right)$ and the parameter estimation error $\left(e_{a}(t), e_{b}(t), e_{c}(t), e_{p}(t)\right)$ are globally bounded, i.e.

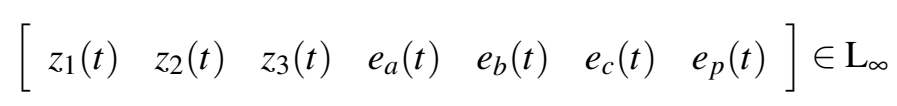

Also, it follows from (45) that

$$
\dot{V} \leqslant-z_{1}^{2}-z_{2}^{2}-z_{3}^{2}=-\|\mathbf{z}\|^{2}
$$

That is,

$$
\|\mathbf{z}\|^{2} \leqslant-\dot{V}
$$


Integrating the inequality (48) from 0 to $t$, we get

$$
\int_{0}^{t}|z(\tau)|^{2} d \tau \leqslant V(0)-V(t)
$$

From (49), it follows that $\boldsymbol{z}(t) \in \mathrm{L}_{2}$.

From Eq. (22), it can be deduced that $\dot{z}(t) \in \mathrm{L}_{\infty}$.

Thus, using Barbalat's lemma, we conclude that $z(t) \rightarrow \mathbf{0}$ exponentially as $t \rightarrow \infty$ for all initial conditions $\boldsymbol{z}(0) \in \mathfrak{R}^{3}$.

Hence, it is immediate that $\boldsymbol{x}(t) \rightarrow \mathbf{0}$ exponentially as $t \rightarrow \infty$ for all initial conditions $\boldsymbol{x}(0) \in \mathfrak{R}^{3}$.

This completes the proof.

For the numerical simulations, the classical fourth-order Runge-Kutta method with step size $h=10^{-8}$ is used to solve the system of differential equations (22) and (27), when the adaptive control law (25) is applied.

The parameter values of the novel jerk chaotic system (22) are taken as in the chaotic case (2), i.e.

$$
a=7.5, b=4, c=0.03, p=0.9
$$

The positive gain constant $k$ is taken as $k=10$.

As initial conditions of the novel jerk chaotic system (22), we take

$$
x_{1}(0)=6.2, \quad x_{2}(0)=15.9, \quad x_{3}(0)=9.7
$$

Also, as initial conditions of the parameter estimates, we take

$$
\hat{a}(0)=2.1, \hat{b}(0)=7.3, \quad \hat{c}(0)=5.4, \quad \hat{p}(0)=8.6
$$

In Figure 5, the exponential convergence of the controlled states is depicted, when the adaptive control law (25) and parameter update law (27) are implemented.

\section{Adaptive synchronization of the identical 3-D novel jerk chaotic systems}

In this section, we use backstepping control method to derive an adaptive control law for globally and exponentially synchronizing the identical 3-D novel jerk chaotic systems with unknown parameters.

As the master system, we consider the 3-D novel jerk chaotic system given by

$$
\left\{\begin{array}{l}
\dot{x}_{1}=x_{2} \\
\dot{x}_{2}=x_{3} \\
\dot{x}_{3}=a x_{1}-b x_{2}-x_{3}+c x_{1} x_{2}-p\left(x_{1}^{2}+x_{2}^{2}\right)
\end{array}\right.
$$




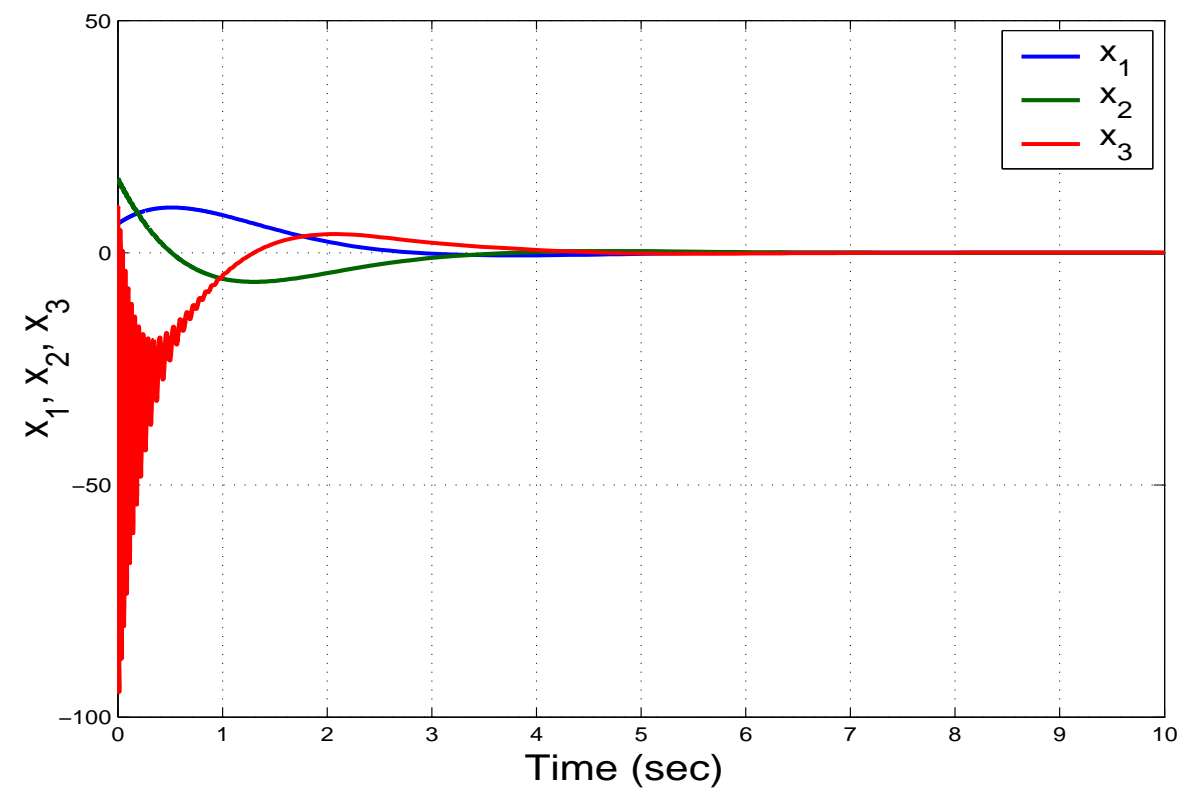

Figure 5. Time-history of the controlled states $x_{1}(t), x_{2}(t), x_{3}(t)$

where $x_{1}, x_{2}, x_{3}$ are the states of the system, and $a, b, c, p$ are unknown constant parameters.

As the slave system, we consider the 3-D novel jerk chaotic system given by

$$
\left\{\begin{array}{l}
\dot{y_{1}}=y_{2} \\
\dot{y_{2}}=y_{3} \\
\dot{y_{3}}=a y_{1}-b y_{2}-y_{3}+c y_{1} y_{2}-p\left(y_{1}^{2}+y_{2}^{2}\right)+u
\end{array}\right.
$$

where $y_{1}, y_{2}, y_{3}$ are the states of the system, and $u$ is a backstepping control to be determined using estimates of the unknown system parameters.

We define the synchronization errors between the states of the master system (53) and the slave system (54) as

$$
\left\{\begin{array}{l}
e_{1}=y_{1}-x_{1} \\
e_{2}=y_{2}-x_{2} \\
e_{3}=y_{3}-x_{3}
\end{array}\right.
$$


Then the error dynamics is easily obtained as

$$
\left\{\begin{aligned}
\dot{e}_{1}= & e_{2} \\
\dot{e}_{2}= & e_{3} \\
\dot{e}_{3}= & a e_{1}-b e_{2}-e_{3}+c\left(y_{1} y_{2}-x_{1} x_{2}\right) \\
& -p\left(y_{1}^{2}-x_{1}^{2}+y_{2}^{2}-x_{2}^{2}\right)+u
\end{aligned}\right.
$$

The parameter estimation errors are defined as:

$$
\left\{\begin{array}{l}
e_{a}(t)=a-\hat{a}(t) \\
e_{b}(t)=b-\hat{b}(t) \\
e_{c}(t)=c-\hat{c}(t) \\
e_{p}(t)=p-\hat{p}(t)
\end{array}\right.
$$

Differentiating (57) with respect to $t$, we obtain the following equations:

$$
\left\{\begin{array}{r}
\dot{e}_{a}(t)=-\dot{\hat{a}}(t) \\
\dot{e}_{b}(t)=-\dot{\hat{b}}(t) \\
\dot{e}_{c}(t)=-\dot{\hat{c}}(t) \\
\dot{e}_{p}(t)=-\dot{\hat{p}}(t)
\end{array}\right.
$$

Next, we shall state and prove the main result of this section.

Theorem 2 The identical 3-D novel jerk chaotic systems (53) and (54) with unknown parameters $a$ and $b$ are globally and exponentially synchronized by the adaptive control law

$$
\left\{\begin{aligned}
u(t)= & -[3+\hat{a}(t)] e_{1}-[5-\hat{b}(t)] e_{2}-2 e_{3}-\hat{c}(t)\left[y_{1} y_{2}-x_{1} x_{2}\right] \\
& +\hat{p}(t)\left[y_{1}^{2}-x_{1}^{2}+y_{2}^{2}-x_{2}^{2}\right]-k z_{3}
\end{aligned}\right.
$$

where $k>0$ is a gain constant,

$$
z_{3}=2 e_{1}+2 e_{2}+e_{3}
$$

and the update law for the parameter estimates $\hat{a}(t), \hat{b}(t)$ is given by

$$
\left\{\begin{array}{l}
\dot{\hat{a}}(t)=e_{1} z_{3} \\
\dot{\hat{b}}(t)=-e_{2} z_{3} \\
\dot{\hat{c}}(t)=\left(y_{1} y_{2}-x_{1} x_{2}\right) z_{3} \\
\dot{\hat{p}}(t)=-\left(y_{1}^{2}-x_{1}^{2}+y_{2}^{2}-x_{2}^{2}\right) z_{3}
\end{array}\right.
$$


Proof We prove this result via backstepping control method and Lyapunov stability theory.

First, we define a quadratic Lyapunov function

$$
V_{1}\left(z_{1}\right)=\frac{1}{2} z_{1}^{2}
$$

where

$$
z_{1}=e_{1}
$$

Differentiating $V_{1}$ along the error dynamics (56), we get

$$
\dot{V}_{1}=z_{1} \dot{z}_{1}=e_{1} e_{2}=-z_{1}^{2}+z_{1}\left(e_{1}+e_{2}\right)
$$

Now, we define

$$
z_{2}=e_{1}+e_{2}
$$

Using (65), we can simplify the equation (64) as

$$
\dot{V}_{1}=-z_{1}^{2}+z_{1} z_{2}
$$

Secondly, we define a quadratic Lyapunov function

$$
V_{2}\left(z_{1}, z_{2}\right)=V_{1}\left(z_{1}\right)+\frac{1}{2} z_{2}^{2}=\frac{1}{2}\left(z_{1}^{2}+z_{2}^{2}\right)
$$

Differentiating $V_{2}$ along the error dynamics (56), we get

$$
\dot{V}_{2}=-z_{1}^{2}-z_{2}^{2}+z_{2}\left(2 e_{1}+2 e_{2}+e_{3}\right)
$$

Now, we define

$$
z_{3}=2 e_{1}+2 e_{2}+e_{3}
$$

Using (69), we can simplify the equation (68) as

$$
\dot{V}_{2}=-z_{1}^{2}-z_{2}^{2}+z_{2} z_{3}
$$

Finally, we define a quadratic Lyapunov function

$$
V\left(z_{1}, z_{2}, z_{3}, e_{a}, e_{b}, e_{c}, e_{p}\right)=V_{2}\left(z_{1}, z_{2}\right)+\frac{1}{2} z_{3}^{2}+\frac{1}{2}\left(e_{a}^{2}+e_{b}^{2}+e_{c}^{2}+e_{p}^{2}\right)
$$

which is a positive definite function on $\Re^{7}$.

Differentiating $V$ along the error dynamics (56), we get

$$
\dot{V}=-z_{1}^{2}-z_{2}^{2}-z_{3}^{2}+z_{3}\left(z_{3}+z_{2}+\dot{z}_{3}\right)-e_{a} \dot{\hat{a}}-e_{b} \dot{\hat{b}}-e_{c} \dot{\hat{c}}-e_{p} \dot{\hat{p}}
$$

Eq. (72) can be written compactly as

$$
\dot{V}=-z_{1}^{2}-z_{2}^{2}-z_{3}^{2}+z_{3} S-e_{a} \dot{\hat{a}}-e_{b} \dot{\hat{b}}-e_{c} \dot{\hat{c}}-e_{p} \dot{\hat{p}}
$$


where

$$
S=z_{3}+z_{2}+\dot{z}_{3}=z_{3}+z_{2}+2 \dot{e}_{1}+2 \dot{e}_{2}+\dot{e}_{3}
$$

A simple calculation gives

$$
S=(3+a) e_{1}+(5-b) e_{2}+2 e_{3}+c\left(y_{1} y_{2}-x_{1} x_{2}\right)-p\left(y_{1}^{2}-x_{1}^{2}+y_{2}^{2}-x_{2}^{2}\right)+u
$$

Substituting the adaptive control law (59) into (41), we obtain

$$
\left\{\begin{aligned}
S= & {[a-\hat{a}(t)] e_{1}-[b-\hat{b}(t)] e_{2}+[c-\hat{c}(t)]\left(y_{1} y_{2}-x_{1} x_{2}\right) } \\
& -[p-\hat{p}(t)]\left(y_{1}^{2}-x_{1}^{2}+y_{2}^{2}-x_{2}^{2}\right)-k z_{3}
\end{aligned}\right.
$$

Using the definitions (58), we can simplify (76) as

$$
S=e_{a} e_{1}-e_{b} e_{2}+e_{c}\left(y_{1} y_{2}-x_{1} x_{2}\right)-e_{p}\left(y_{1}^{2}-x_{1}^{2}+y_{2}^{2}-x_{2}^{2}\right)-k z_{3}
$$

Substituting the value of $S$ from (77) into (73), we obtain

$$
\left\{\begin{aligned}
\dot{V}= & -z_{1}-z_{2}-(1+k) z_{3}^{2}+e_{a}\left[e_{1} z_{3}-\dot{\hat{a}}\right]+e_{b}\left[-e_{2} z_{3}-\dot{\hat{b}}\right] \\
& +e_{c}\left[\left(y_{1} y_{2}-x_{1} x_{2}\right) z_{3}-\dot{\hat{c}}\right]+e_{p}\left[-\left(y_{1}^{2}-x_{1}^{2}+y_{2}^{2}-x_{2}^{2}\right) z_{3}-\dot{\hat{p}}\right]
\end{aligned}\right.
$$

Substituting the update law (61) into (78), we get

$$
\dot{V}=-z_{1}^{2}-z_{2}^{2}-(1+k) z_{3}^{2}
$$

which is a negative semi-definite function on $\mathfrak{R}^{7}$.

From (79), it follows that the vector $z(t)=\left(z_{1}(t), z_{2}(t), z_{3}(t)\right)$ and the parameter estimation error $\left(e_{a}(t), e_{b}(t), e_{c}(t), e_{p}(t)\right)$ are globally bounded, i.e.

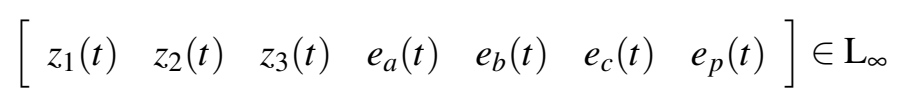

Also, it follows from (79) that

$$
\dot{V} \leqslant-z_{1}^{2}-z_{2}^{2}-z_{3}^{2}=-\|\mathbf{z}\|^{2}
$$

That is,

$$
\|\mathbf{z}\|^{2} \leqslant-\dot{V}
$$

Integrating the inequality (82) from 0 to $t$, we get

$$
\int_{0}^{t}|z(\tau)|^{2} d \tau \leqslant V(0)-V(t)
$$

From (83), it follows that $z(t) \in \mathrm{L}_{2}$. 
From Eq. (56), it can be deduced that $\dot{z}(t) \in \mathrm{L}_{\infty}$.

Thus, using Barbalat's lemma, we conclude that $z(t) \rightarrow \mathbf{0}$ exponentially as $t \rightarrow \infty$ for all initial conditions $\boldsymbol{z}(0) \in \mathfrak{R}^{3}$.

Hence, it is immediate that $\boldsymbol{e}(t) \rightarrow \mathbf{0}$ exponentially as $t \rightarrow \infty$ for all initial conditions $\boldsymbol{e}(0) \in \mathfrak{R}^{3}$.

This completes the proof.

For the numerical simulations, the classical fourth-order Runge-Kutta method with step size $h=10^{-8}$ is used to solve the system of differential equations (53) and (54).

The parameter values of the novel jerk chaotic systems are taken as

$$
a=7.5, \quad b=4, \quad c=0.03, \quad p=0.9
$$

The positive gain constant is taken as $k=10$.

As initial conditions of the master chaotic system (53), we take

$$
x_{1}(0)=5.2, \quad x_{2}(0)=6.7, \quad x_{3}(0)=-8.1
$$

As initial conditions of the slave chaotic system (54), we take

$$
y_{1}(0)=-3.7, \quad y_{2}(0)=12.4, \quad y_{3}(0)=7.5
$$

Also, as initial conditions of the parameter estimates, we take

$$
\hat{a}(0)=8.2, \quad \hat{b}(0)=10.1, \hat{c}(0)=5.6, \hat{p}(0)=2.3
$$

In Figs. 6-8, the complete synchronization of the identical 3-D jerk chaotic systems (53) and (54) is shown, when the adaptive control law and the parameter update law are impelemented.

Also, in Fig. 9, the time-history of the synchronization errors $e_{1}(t), e_{2}(t), e_{3}(t)$, is shown.

\section{Conclusions}

In this paper, we announced an eight-term novel 3-D jerk chaotic system with three quadratic nonlinearities. The phase portraits of the novel jerk chaotic system were displayed and the mathematical properties were discussed. We showed that the novel jerk chaotic system has two equilibrium points, which are saddle-foci and unstable. The Lyapunov exponents of the novel jerk chaotic system have been obtained as $L_{1}=0.20572, L_{2}=0$ and $L_{3}=-1.20824$. Since the sum of the Lyapunov exponents of the jerk chaotic system is negative, we conclude that the chaotic system is dissipative. The Kaplan-Yorke dimension of the novel jerk chaotic system has been derived as $D_{K Y}=2.17026$. 


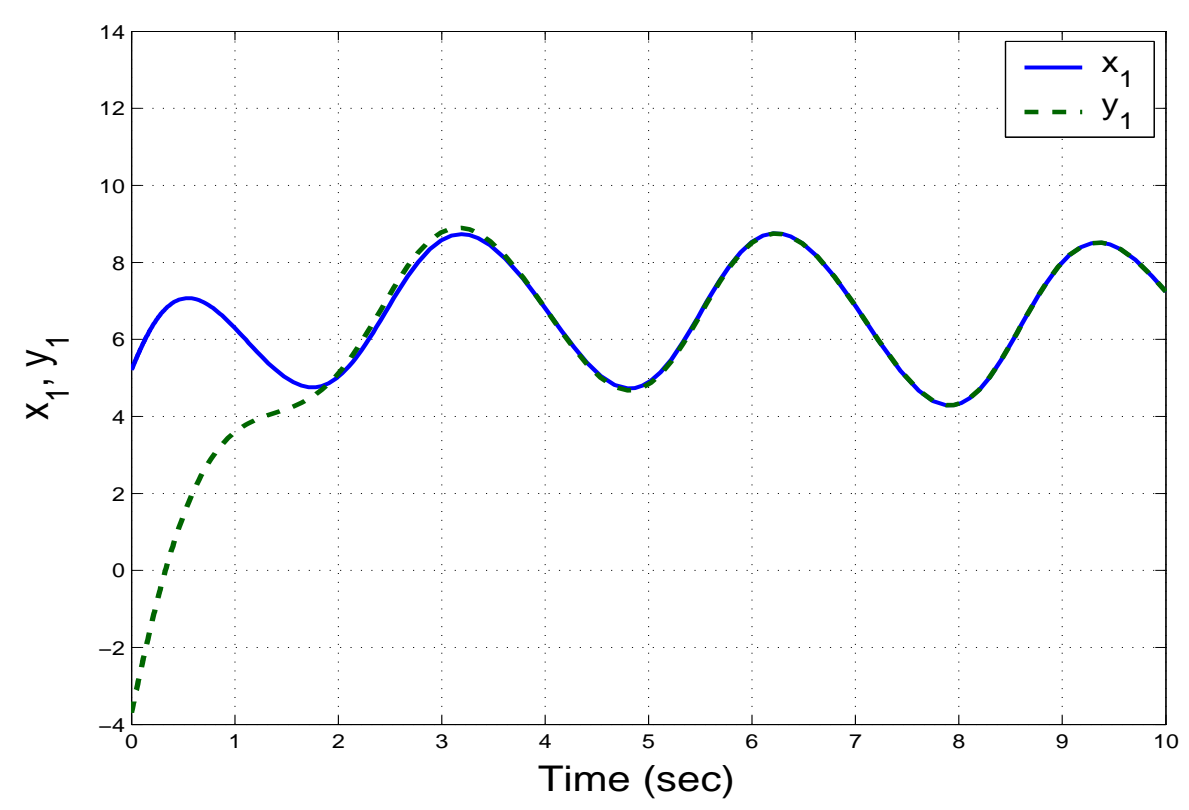

Figure 6. Synchronization of the states $x_{1}(t)$ and $y_{1}(t)$

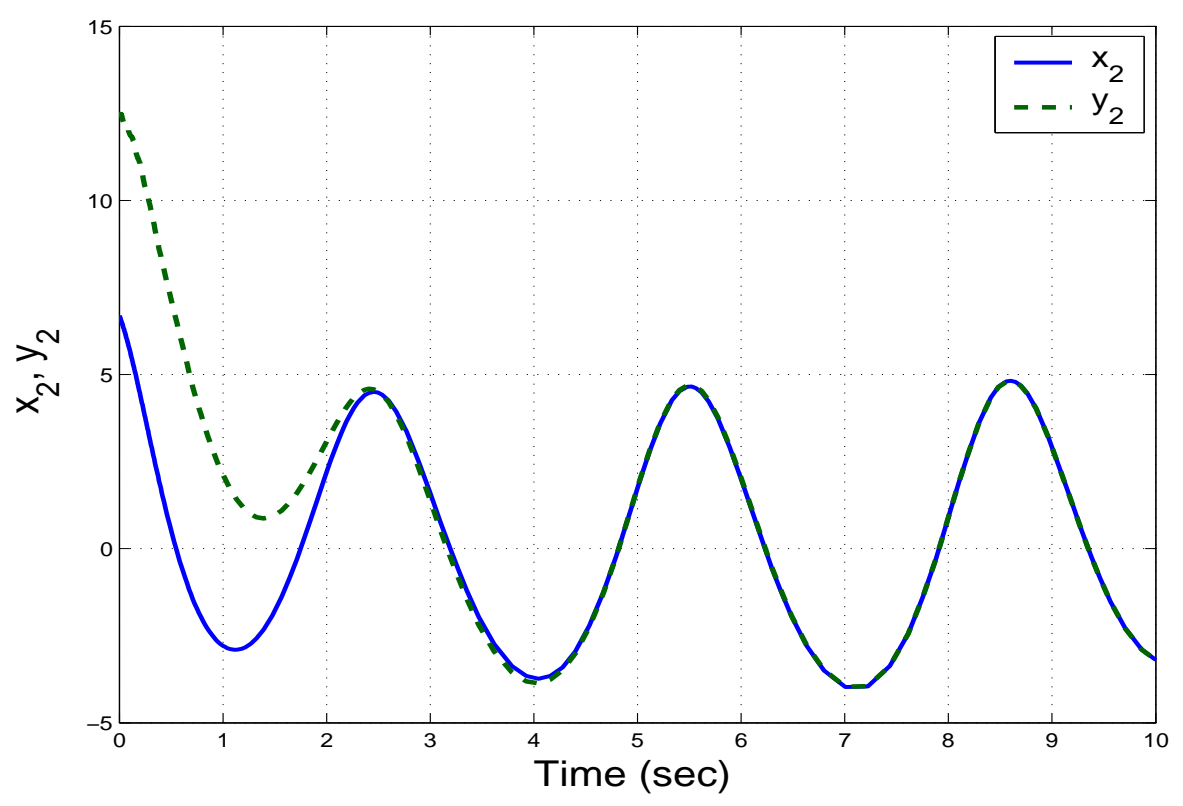

Figure 7. Synchronization of the states $x_{2}(t)$ and $y_{2}(t)$ 


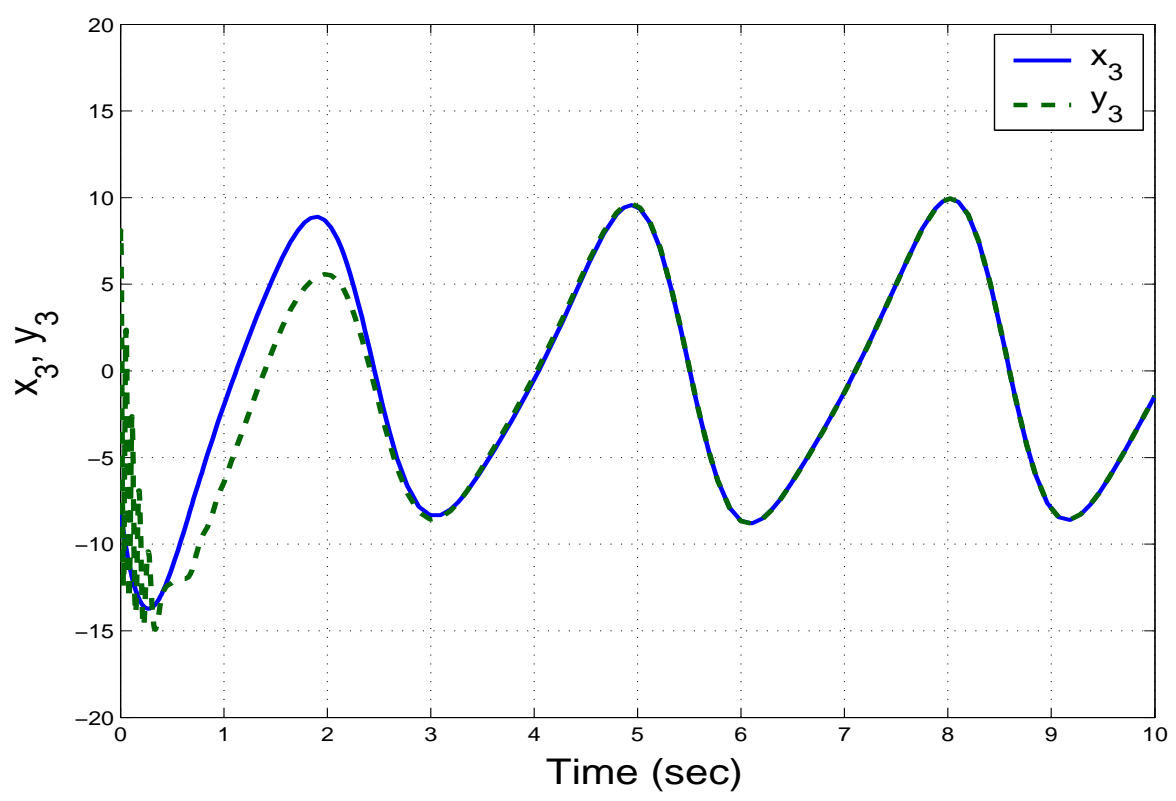

Figure 8. Synchronization of the states $x_{3}(t)$ and $y_{3}(t)$

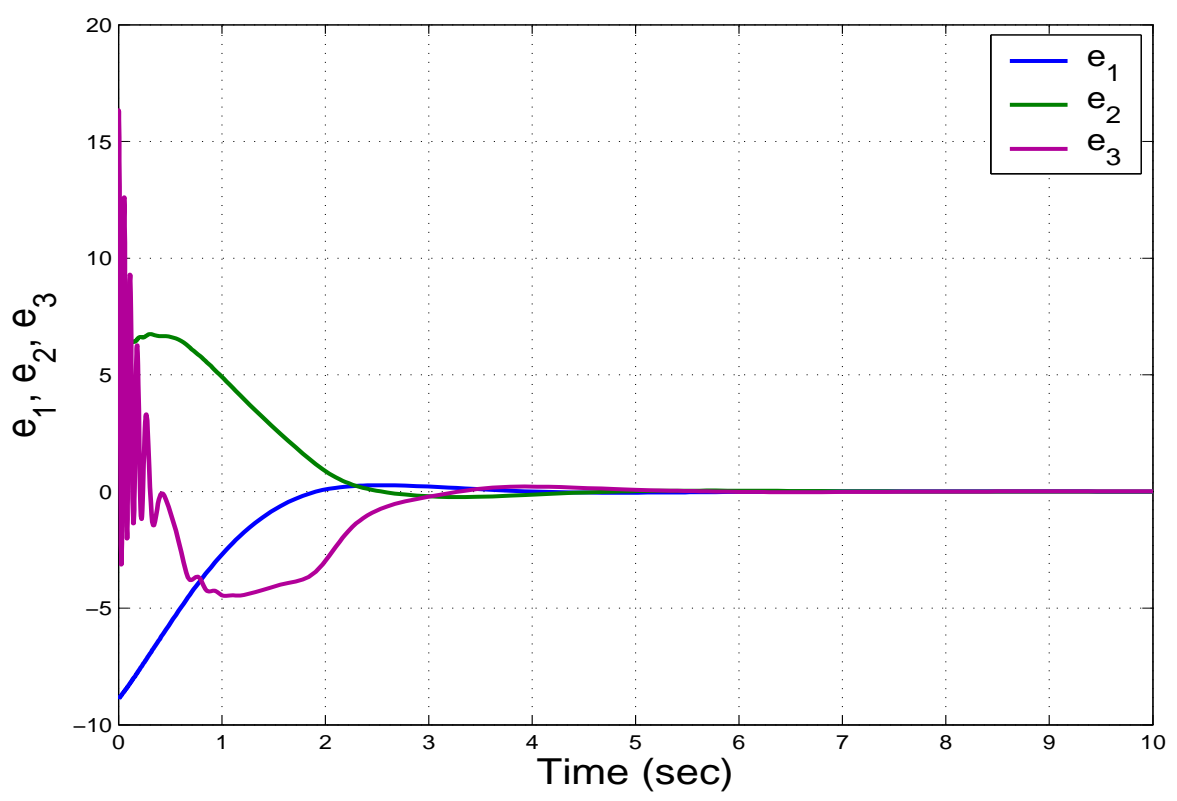

Figure 9. Time-history of the synchronization errors $e_{1}(t), e_{2}(t), e_{3}(t)$ 
Next, an adaptive controller was designed via backstepping control method to globally stabilize the novel jerk chaotic system with unknown parameters. Moreover, an adaptive controller was also designed via backstepping control method to achieve global chaos synchronization of the identical jerk chaotic systems with unknown parameters. The backstepping control method is a recursive procedure that links the choice of a Lyapunov function with the design of a controller and guarantees global asymptotic stability of strict feedback systems. MATLAB simulations were depicted to illustrate the phase portraits of the novel jerk chaotic system and also the adaptive backstepping control results.

\section{References}

[1] K.T. ALLIGOOD, T.D. SAUER and J.A. YORKE: Chaos: An introduction to Dynamical Systems. New York, Springer-Verlag, 2000.

[2] E.N. LORENZ: Deterministic nonperiodic flow. Journal of the Atmospheric Sciences, 20 (1963), 130-141.

[3] O.E. RÖSSLER: An equation for continuous chaos. Physics Letters A, 57 (1976), 397-398.

[4] A. ARNEODO, P. COULLET and C. TRESSER: Possible new strange attractors with spiral structure. Communications in Mathematical Physics, 79 (1981), 573579.

[5] J.C. SPROTT: Some simple chaotic flows. Physical Review E, 50 (1994), 647650 .

[6] G. CHEN and T. UETA: Yet another chaotic attractor. International Journal of Bifurcation and Chaos, 9 (1999), 1465-1466.

[7] M. HÉNON and C. HEILES: The applicability of the third integral of motion: Some numerical experiments. Astrophysical Journal, 69 (1964), 73-79.

[8] J. LÜ and G. CHEN: A new chaotic attractor coined. International Journal of Bifurcation and Chaos, 12 (2002), 659-661.

[9] C.X. LIU, T. LIU, L. LIU and K. LIU: A new chaotic attractor. Chaos, Solitons and Fractals, 22 (2004), 1031-1038.

[10] G. CAI and Z. TAN: Chaos synchronization of a new chaotic system via nonlinear control. Journal of Uncertain Systems, 1 (2007), 235-240.

[11] G. TIGAN and D. OPRIS: Analysis of a 3D chaotic system. Chaos, Solitons and Fractals, 36 (2008), 1315-1319. 
[12] D. LI: A three-scroll chaotic attractor. Physics Letters A, 372 (2008), 387-393.

[13] V. SUNDARAPANDIAN and I. PEHLIVAN: Analysis, control, synchronization and circuit design of a novel chaotic system. Mathematical and Computer Modelling, 55 (2012), 1904-1915.

[14] V. SUNDARAPANDIAN: Analysis and anti-synchronization of a novel chaotic system via active and adaptive controllers. Journal of Engineering Science and Technology Review, 6 (2013), 45-52.

[15] S. VAIDYANATHAN: A new six-term 3-D chaotic system with an exponential nonlinearity. Far East Journal of Mathematical Sciences, 79 (2013), 135-143.

[16] S. VAIDYANATHAN: Analysis and adaptive synchronization of two novel chaotic systems with hyperbolic sinusoidal and cosinusoidal nonlinearity and unknown parameters. Journal of Engineering Science and Technology Review, 6 (2013), 53-65.

[17] S. VAIDYANATHAN: A new eight-term 3-D polynomial chaotic system with three quadratic nonlinearities. Far East Journal of Mathematical Sciences, 84 (2014), 219-226.

[18] S. VAIDYANATHAN: Analysis, control and synchronisation of a six-term novel chaotic system with three quadratic nonlinearities. International Journal of Modelling, Identification and Control, 22 (2014), 41-53.

[19] S. VAIDYANATHAN and K. MADHAVAN: Analysis, adaptive control and synchronization of a seven-term novel 3-D chaotic system. International Journal of Control Theory and Applications, 6 (2013), 121-137.

[20] S. VAIDYANATHAN: Analysis and adaptive synchronization of eight-term 3-D polynomial chaotic systems with three quadratic nonlinearities. European Physical Journal: Special Topics, 223 (2014), 1519-1529.

[21] S. VAIDYANATHAN, CH. VOLOS, V.T. PHAM, K. MADHAVAN and B.A. IDOWU: Adaptive backstepping control, synchronization and circuit simulation of a 3-D novel jerk chaotic system with two hyperbolic sinusoidal nonlinearities. Archives of Control Sciences, 24 (2014), 257-285.

[22] S. VAIDYANATHAN: Generalised projective synchronisation of novel 3-D chaotic systems with an exponential non-linearity via active and adaptive control. International Journal of Modelling, Identification and Control, 22 (2014), 207-217.

[23] S. VAIDYANATHAN: Analysis, properties and control of an eight-term 3-D chaotic system with an exponential nonlinearity. International Journal of Modelling, Identification and Control, 23 (2015), 164-172. 
[24] S. VAIDYANATHAN: A 3-D novel highly chaotic system with four quadratic nonlinearities, its adaptive control and anti-synchronization with unknown parameters. Journal of Engineering Science and Technology Review, 8 (2015), 106-115.

[25] S. VAIDYANATHAN, K. RAJAGOPAL, C.K. VOLOS, I.M. KYPRIANIDIS and I.N. STOUBOULOS: Analysis, adaptive control and synchronization of a seventerm novel 3-D chaotic system with three quadratic nonlinearities and its digital implementation in LabVIEW. Journal of Engineering Science and Technology Review, 8 (2015), 130-141.

[26] S. VAIDYANATHAN, C.K. VOLOS, I.M. KYPRIANIDIS, I.N. STOUBOULOS and V.-T. PHAM: Analysis, adaptive control and anti-synchronization of a sixterm novel jerk chaotic system with two exponential nonlinearities and its circuit simulation. Journal of Engineering Science and Technology Review, 8 (2015), 2436.

[27] S. VAIDYANATHAN, C.K. VOLOS and V.-T. PHAM: Analysis, adaptive control and adaptive synchronization of a nine-term novel 3-D chaotic system with four quadratic nonlinearities and its circuit simulation. Journal of Engineering Science and Technology Review, 8 (2015), 174-184.

[28] S. VAIDYANATHAN and C. VOLOS: Analysis and adaptive control of a novel 3-D conservative no-equilibrium chaotic system. Archives of Control Sciences, 25 (2015), 333-353.

[29] S. VAIDYANATHAN: Analysis, control, and synchronization of a 3-D novel jerk chaotic system with two quadratic nonlinearities. Kyungpook Mathematical Journal, 55 (2015), 563-586.

[30] S. VAIDYANATHAN and S. PAKIRISWAMY: A 3-D novel conservative chaotic system and its generalized projective synchronization via adaptive control. Journal of Engineering Science and Technology Review, 8 (2015), 52-60.

[31] I. PEHLIVAN, I.M. MOROZ and S. VAIDYANATHAN: Analysis, synchronization and circuit design of a novel butterfly attractor. Journal of Sound and Vibration, 333 (2014), 5077-5096.

[32] O.I. TACHA, C.K. VOLOS, I.M. KYPRIANIDIS, I.N. STOUBOULOS, S. VAIDYANATHAN and V.-T. PHAM: Analysis, adaptive control and circuit simulation of a novel nonlinear finance system. Applied Mathematics and Computation, 276 (2016), 200-217.

[33] S. JAFARI and J.C. SPROTT: Simple chaotic flows with a line equilibrium. Chaos, Solitons and Fractals, 57 (2013), 79-84. 
[34] S. SAMPATH, S. VAIDYANATHAN, C.K. VOLOS and V.T. PHAM: An eightterm novel four-scroll chaotic system with cubic nonlinearity and its circuit simulation. Journal of Engineering Science and Technology Review, 8 (2015), 1-6.

[35] V.T. PHAM, C. VOLOS, S. JAFARI, Z. WEI and X. WANG: Constructing a novel no-equilibrium chaotic system. International Journal of Bifurcation and Chaos, 24 (2014), 1450073.

[36] V.T. PHAM, S. VAIDYANATHAN, C.K. VOLOS and S. JAFARI: Hidden attractors in a chaotic system with an exponential nonlinear term. European Physical Journal: Special Topics, 224 (2015), 1507-1517.

[37] V.T. PHAM, S. VAIDYANATHAN, C. VOLOS, S. JAFARI and S.T. KINGNI: A no-equilibrium hyperchaotic system with a cubic nonlinear term. Optik, 127 (6), (2016), 3259-3265.

[38] V.T. PHAM, C. VOLOS and S. VAIDYANATHAN: Chaotic attractor in a novel time-delayed system with a saturation function. Handbook of Research on Advanced Intelligence Control Engineering and Automation, (2015), pp. 230-258.

[39] S. VAIDYANATHAN: Anti-synchronization of Mathieu-Van der Pol chaotic systems via adaptive control method. International Journal of ChemTech Research, 8 (11), (2015), 638-653.

[40] S. VAIDYANATHAN: Global chaos synchronization of novel coupled Van der Pol conservative chaotic systems via adaptive control method. International Journal of PharmTech Research, 8 (8), (2015), 95-111.

[41] S. VAIDYANATHAN: Global chaos synchronization of the forced Van der Pol chaotic oscillators via adaptive control method. International Journal of PharmTech Research, 8 (6), (2015), 156-166.

[42] S. VAIDYANATHAN: Sliding controller design for the global chaos synchronization of forced Van der Pol chaotic oscillators. International Journal of PharmTech Research, 8 (7), (2015), 100-111.

[43] S. VAIDYANATHAN: Output regulation of the forced Van der Pol chaotic oscillator via adaptive control method. International Journal of PharmTech Research, 8 (6), (2015), 106-116.

[44] S. VAIDYANATHAN: Global chaos synchronization of Mathieu-Van der Pol chaotic systems via adaptive control method. International Journal of ChemTech Research, 8 (10), (2015), 148-162.

[45] S. VAIDYANATHAN: A novel coupled Van der Pol conservative chaotic system and its adaptive control. International Journal of PharmTech Research, 8 (8), (2015), 79-94. 
[46] S. VAIDYANATHAN: Global chaos synchronization of Duffing double-well chaotic oscillators via integral sliding mode control. International Journal of ChemTech Research, 8 (11), (2015), 141-151.

[47] S. VAIDYANATHAN: Adaptive synchronization of Rikitake two-disk dynamo chaotic systems. International Journal of ChemTech Research, 8 (8), (2015), 100111.

[48] S. VAIDYANATHAN: Anti-synchronization of Rikitake two-disk dynamo chaotic systems via adaptive control method. International Journal of ChemTech Research, 8 (9), (2015), 393-405.

[49] S. VAIDYANATHAN, C.K. VOLOS and V.T. PHAM: Analysis, control, synchronization and SPICE implementation of a novel 4-D hyperchaotic Rikitake dynamo system without equilibrium. Journal of Engineering Science and Technology Review, 8 (2), (2015), 232-244.

[50] S. VAIDYANATHAN, V.T. PHAM and C.K. VOLOS: A 5-D hyperchaotic Rikitake dynamo system with hidden attractors. European Physical Journal: Special Topics, 224 (8), (2015), 1575-1592.

[51] S. VAIDYANATHAN: Synchronization of Tokamak systems with symmetric and magnetically confined plasma via adaptive control. International Journal of ChemTech Research, 8 (6), (2015), 818-827.

[52] S. VAIDYANATHAN: Dynamics and control of Tokamak system with symmetric and magnetically confined plasma. International Journal of ChemTech Research, 8 (6), (2015), 795-803.

[53] S. VAIDYANATHAN: Anti-synchronization of chemical chaotic reactors via adaptive control method. International Journal of ChemTech Research, 8 (8), (2015), 73-85.

[54] S. VAIDYANATHAN: Adaptive control of a chemical chaotic reactor. International Journal of PharmTech Research, 8 (3), (2015), 377-382.

[55] S. VAIDYANATHAN: Global chaos synchronization of chemical chaotic reactors via novel sliding mode control method. International Journal of ChemTech Research, 8 (7), (2015), 209-221.

[56] S. VAIDYANATHAN: A novel chemical chaotic reactor system and its output regulation via integral sliding mode control. International Journal of ChemTech Research, 8 (11), (2015), 669-683.

[57] S. VAIDYANATHAN: Integral sliding mode control design for the global chaos synchronization of identical novel chemical chaotic reactor systems. International Journal of ChemTech Research, 8 (11), (2015), 684-699. 
[58] S. VAIDYANATHAN: Adaptive control design for the anti-synchronization of novel 3-D chemical chaotic reactor systems. International Journal of ChemTech Research, 8 (11), (2015), 654-668.

[59] S. VAIDYANATHAN: Adaptive synchronization of chemical chaotic reactors. International Journal of ChemTech Research, 8 (2), (2015), 612-621.

[60] S. VAIDYANATHAN: A novel chemical reactor system and its adaptive control. International Journal of ChemTech Research, 8 (7), (2015), 146-158.

[61] S. VAIDYANATHAN: Adaptive synchronization of novel 3-D chemical chaotic reactor systems. International Journal of ChemTech Research, 8 (7), (2015), 159171.

[62] S. VAIDYANATHAN: Anti-synchronization of Brusselator chemical reaction systems via adaptive control. International Journal of ChemTech Research, 8 (6), (2015), 759-768.

[63] S. VAIDYATHAN: 3-cells cellular neural network (CNN) attractor and its adaptive biological control. International Journal of PharmTech Research, 8 (4), (2015), 632-640.

[64] S. VAIDYATHAN: Hybrid chaos synchronization of 3-cells cellular neural network attractors via adaptive control method. International Journal of PharmTech Research, 8 (8), (2015), 61-73.

[65] S. VAIDYATHAN: Synchronization of 3-cells cellular neural network (CNN) attractors via adaptive control method. International Journal of PharmTech Research, 8 (5), (2015), 946-955.

[66] S. VAIDYATHAN: Global chaos control of 3-cells cellular neural network attractor via integral sliding mode control. International Journal of PharmTech Research, 8 (8), (2015), 211-221.

[67] S. VAIDYATHAN: Global chaos synchronization of 3-cells cellular neural network attractors via integral sliding mode control. International Journal of PharmTech Research, 8 (8), (2015), 118-130.

[68] S. VAIDYATHAN: Anti-synchronization of 3-cells cellular neural network attractors via adaptive control method. International Journal of PharmTech Research, 8 (7), (2015), 26-38.

[69] S. VAIDYATHAN: Adaptive chaotic synchronization of enzymes-substrates system with ferroelectric behaviour in brain waves. International Journal of PharmTech Research, 8 (5), (2015), 964-973. 
[70] S. VAIDYATHAN: Adaptive backstepping control of enzymes-substrates system with ferroelectric behaviour in brain waves. International Journal of PharmTech Research, 8 (2), (2015), 256-261.

[71] S. VAIDYATHAN: Sliding controller design for the global chaos synchronization of enzymes-substrates systems. International Journal of PharmTech Research, 8 (7), (2015), 89-99.

[72] S. VAIDYATHAN: Anti-synchronization of the FitzHugh-Nagumo chaotic neuron models via adaptive control method. International Journal of PharmTech Research, 8 (7), (2015), 71-83.

[73] S. VAIDYATHAN: Adaptive control of the FitzHugh-Nagumo chaotic neuron model. International Journal of PharmTech Research, 8 (6), (2015), 117-127.

[74] S. VAIDYATHAN: Adaptive synchronization of the identical FitzHugh-Nagumo chaotic neuron models. International Journal of PharmTech Research, 8 (6), (2015), 167-177.

[75] S. VAIDYATHAN: Active control design for the anti-synchronization of LotkaVolterra biological systems with four competitive species. International Journal of PharmTech Research, 8 (7), (2015), 58-70.

[76] S. VAIDYATHAN: Chaos in neurons and adaptive control of Birkhoff-Shaw strange chaotic attractor. International Journal of PharmTech Research, 8 (5), (2015), 956-963.

[77] S. VAIDYATHAN: Global chaos synchronization of the Lotka-Volterra biological systems with four competitive species via active control. International Journal of PharmTech Research, 8 (6), (2015), 206-217.

[78] S. VAIDYATHAN: Active control design for the hybrid chaos synchronization of the Lotka-Volterra biological systems with four competitive species. International Journal of PharmTech Research, 8 (8), (2015), 30-42.

[79] S. VAIDYATHAN: Adaptive biological control of generalized Lotka-Volterra three-species biological system. International Journal of PharmTech Research, 8 (4), (2015), 622-631.

[80] S. VAIDYATHAN: Adaptive synchronization of generalized Lotka-Volterra threespecies biological systems. International Journal of PharmTech Research, 8 (5), (2015), 928-937.

[81] S. VAIDYATHAN: Anti-synchronization of the generalized Lotka-Volterra three-species biological systems via adaptive control. International Journal of PharmTech Research, 8 (8), (2015), 141-156. 
[82] S. VAIDYATHAN: Global chaos synchronization of Rucklidge chaotic systems for double convection via sliding mode control. International Journal of ChemTech Research, 8 (8), (2015), 61-72.

[83] S. VAIDYATHAN: Sliding mode control of Rucklidge chaotic system for nonlinear double convection. International Journal of ChemTech Research, 8 (8), (2015), 25-35.

[84] A.E. MATOUK: Chaos, feedback control and synchronization of a fractionalorder modified autonomous Van der PolÜDuffing circuit. Communications in Nonlinear Science and Numerical Simulation, 16 (2011), 975-986.

[85] CH.K. VOLOS, I.M. KYPRIANIDIS, I.N. STOUBOULOS and A.N. ANAGNOSTOPOULOS: Experimental study of the dynamic behavior of a double scroll circuit. Journal of Applied Functional Analysis, 4 (2009), 703-711.

[86] CH.K. VOLOS, V.-T. PHAM, S. VAIDYANATHAN, I.M. KYPRIANIDIS and I.N. STOUBOULOS: Synchronization phenomena in coupled Colpitts circuits. Journal of Engineering Science and Technology Review, 8 (2015), 142-151.

[87] CH.K. VOLOS, I.M. KYRPIANIDIS and I.N. STOUBOULOS: Image encryption process based on chaotic synchronization phenomena. Signal Processing, 93 (2013), 1328-1340.

[88] CH.K. VOLOS, I.M. KYRPIANIDIS and I.N. STOUBOULOS: Text encryption scheme realized with a chaotic pseudo-random bit generator. Journal of Engineering Science and Technology Review, 6 (2013), 9-14.

[89] V.-T. PHAM, C. VOLOS, S. JAFARI, X. WANG and S. VAIDYANATHAN: Hidden hyperchaotic attractor in a novel simple memristive neural network. Optoelectronics and Advanced Materials, Rapid Communications, 8 (2014) 1157-1163.

[90] V.-T. PHAM, CH.K. VOLOS, S. VAIDYANATHAN, T.P. LE and V.Y. VU: A memristor-based hyperchaotic system with hidden attractors: Dynamics, synchronization and circuital emulating. Journal of Engineering Science and Technology Review, 8 (2015), 205-214.

[91] CH.K. VOLOS, I.M. KYPRIANIDIS, I.N. STOUBOULOS, E. TLELOCUAUTLE and S. VAIDYANATHAN: Memristor: A new concept in synchronization of coupled neuromorphic circuits. Journal of Engineering Science and Technology Review, 8 (2015), 157-173.

[92] C. VOLOS, I. KYPRIANIDIS, I. STOUBOULOS and S. VAIDYANATHAN: Random bit generator based on non-autonomous chaotic systems. Handbook of Research on Advanced Intelligent Control Engineering and Automation, (2015), 203-229. 
[93] B.A. IDOWU, U.E. VINCENT and A.N. NJAH: Synchronization of chaos in nonidentical parametrically excited systems. Chaos, Solitons and Fractals, 39 (2009), 2322-2331.

[94] S. VAIDYANATHAN and K. RAJAGOPAL: Hybrid synchronization of hyperchaotic Wang-Chen and hyperchaotic lorenz systems by active non-linear control. International Journal of Signal System Control and Engineering Application, 4 (2011), 55-61.

[95] S. VAIDYANATHAN and S. RASAPPAN: Global chaos synchronization of hyperchaotic Bao and $\mathrm{Xu}$ systems by active nonlinear control. Communications in Computer and Information Science, 198 (2011), 10-17.

[96] S. VAIDYANATHAN: Output regulation of the unified chaotic system. Communications in Computer and Information Science, 198 (2011), 1-9.

[97] S. VAIDYANATHAN, A.T. AZAR, K. RAJAGOPAL and P. ALEXANDER: Design and SPICE implementation of a 12-term novel hyperchaotic system and its synchronisation via active control. International Journal of Modelling, Identification and Control, 23 (2015), 267-277.

[98] V. SUNDARAPANDIAN and R. KARTHIKEYAN: Anti-synchronization of Lü and Pan chaotic systems by adaptive nonlinear control. European Journal of Scientific Research, 64 (2011), 94-106.

[99] V. SUNDARAPANDIAN and R. KARTHIKEYAN: Adaptive antisynchronization of Uncertain Tigan and Li Systems. Journal of Engineering and Applied Sciences, 7 (2012), 45-52.

[100] V. SUNDARAPANDIAN and R. KARTHIKEYAN: Anti-synchronization of hyperchaotic Lorenz and hyperchaotic Chen systems by adaptive control. International Journal of Systems Signal Control and Engineering Application, 4 (2), (2011), 18-25.

[101] P. SARASU and V. SUNDARAPANDIAN: Generalized projective synchronization of three-scroll chaotic systems via adaptive control. European Journal of Scientific Research, 72 (4), (2012), 504-522.

[102] S. VAIDYANATHAN and K. RAJAGOPAL: Global chaos synchronization of hyperchaotic Pang and hyperchaotic Wang systems via adaptive control. International Journal of Soft Computing, 7 (1), (2012), 28-37.

[103] S. VAIDYANATHAN: Hyperchaos, qualitative analysis, control and synchronisation of a ten-term 4-D hyperchaotic system with an exponential nonlinearity and three quadratic nonlinearities. International Journal of Modelling, Identification and Control, 23 (2015), 380-392. 
[104] S. VAIDYANATHAN, V.-T. PHAM and C.K. VOLOS: A 5-D hyperchaotic Rikitake dynamo system with hidden attractors. European Physical Journal: Special Topics, 224 (2015), 1575-1592.

[105] P. SARASU and V. SUNDARAPANDIAN: Adaptive controller design for the generalized projective synchronization of 4-scroll systems. International Journal of Systems Signal Control and Engineering Application, 5 (2), (2012), 21-30.

[106] P. SARASU and V. SUNDARAPANDIAN: Generalized projective synchronization of two-scroll systems via adaptive control. International Journal of Soft Computing, 7 (4), (2012), 146-156.

[107] P. SARASU and V. SUNDARAPANDIAN: Generalized projective synchronization of three-scroll chaotic systems via adaptive control. European Journal of Scientific Research, 72 (4), (2012), 504-522.

[108] S. RASAPPAN and S. VAIDYANATHAN: Synchronization of hyperchaotic Liu system via backstepping control with recursive feedback. Communications in Computer and Information Science, 305 (2012), 212-221.

[109] S. VAIDYANATHAN and S. RASAPPAN: Global chaos synchronization of $n$ scroll Chua circuit and Lur'e system using backstepping control design with recursive feedback. Arabian Journal for Science and Engineering, 39 (2014), 33513364.

[110] S. VAIDYANATHAN, C.K. VOLOS, K. RAJAGOPAL, I.M. KYPRIANIDIS and I.N. STOUBOULOS: Adaptive backstepping controller design for the antisynchronization of identical WINDMI chaotic systems with unknown parameters and its SPICE implementation. Journal of Engineering Science and Technology Review, 8 (2015), 74-82.

[111] S. VAIDYANATHAN, C. VOLOS, V.T. PHAM and K. MADHAVAN: Analysis, adaptive control and synchronization of a novel 4-D hyperchaotic hyperjerk system and its SPICE implementation. Archives of Control Sciences, 25 (1), (2015), 135-158.

[112] S. VAIDYANATHAN, C.K. VOLOS, K. RAJAGOPAL, I.M. KYPRIANIDIS and I.N. STOUBOULS: Adaptive backstepping controller design for the antisynchronization of identical WINDMI chaotic systems with unknown parameters and its SPICE implementation. Journal of Engineering Science and Technology Review, 8 (2), (2015), 74-82.

[113] S. VAIDYANATHAN, B.A. IDOWU and A.T. AZAR: Backstepping controller design for the global chaos synchronization of Sprott's jerk systems. Studies in Computational Intelligence, 581 (2015), 39-58. 
[114] S. VAIDYANATHAN and S. SAMPATH: Global chaos synchronization of hyperchaotic Lorenz systems by sliding mode control. Communications in Computer and Information Science, 205 (2011), 156-164.

[115] V. SUNDARAPANDIAN and S. SIVAPERUMAL: Sliding controller design of hybrid synchronization of four-wing chaotic systems. International Journal of Soft Computing, 6 (5), (2011), 224-231.

[116] S. VAIDYANATHAN: Global chaos synchronisation of identical Li-Wu chaotic systems via sliding mode control. International Journal of Modelling, Identification and Control, 22 (2014), 170-177.

[117] S. VAIDYANATHAN and S. SAMPATH: Anti-synchronization of four-wing chaotic systems via sliding mode control. International Journal of Automation and Computing, 9 (3), (2012), 274-279.

[118] S. VAIDYANATHAN: Global chaos control of hyperchaotic Liu system via sliding control method. International Journal of Control Theory and Applications, 5 (2), (2012), 117-123.

[119] S. VAIDYANATHAN, S. SAMPATH and A.T. AZAR: Global chaos synchronisation of identical chaotic systems via novel sliding mode control method and its application to Zhu system. International Journal of Modelling, Identification and Control, 23 (2015), 92-100.

[120] H.K. KHALIL: Nonlinear Systems. New York, Prentice Hall, 2002. 